\title{
Microfibre pollution hotspots in river sediments adjacent to South Africa's coastline
}

\author{
Stephanie de Villiers* \\ Centre for Coastal Palaeoscience, Nelson Mandela University, PO Box 7700, Port Elizabeth, 6031, South Africa
}

\begin{abstract}
River sediment samples collected in the lower reaches of catchments along South Africa's coastline have microfibre levels ranging from 0 to 567 fibres $/ \mathrm{dm}^{3}$. This range is similar to those of sandy beach sediments along the coast. Much higher microfibre levels are observed in KwaZulu-Natal and the Wild Coast region, compared to the Cape South Coast. There is a significant positive relationship between river sediment microfibre levels, and the percentage of households in the catchment area that do not have access to piped water. The implication is that rural communities that rely on rivers as their primary or only source of water, including for directly washing clothes in, may be significantly contributing to microfibre pollution of freshwater aquatic ecosystems. If microfibre pollution is found to have ecosystem or human health implications such as chemical toxicity or fibre-induced mesothelioma, this will be detrimental to river biota and these communities.
\end{abstract}

Keywords: microfibres, river pollution, sediment, freshwater system

\section{INTRODUCTION}

The global distribution of microplastic debris and its adverse effects on hundreds of marine species worldwide have been well documented (Eriksen et al., 2014). In comparison, the distribution of microplastic debris and potential land-based sources and fluxes (Hurley et al., 2018; Jambeck et al., 2015) are poorly known. There is increasing evidence that synthetic microfibres are the most prevalent type of microplastic debris present in marine and freshwater environments (Browne et al. 2010; Browne et al., 2011; De Villiers, 2018; Hurley et al., 2018; Mani et al., 2015; Mathalon and Hill, 2014; Miller et al., 2017; Naidoo et al., 2015; Nel and Froneman, 2015; Nel et al., 2017; Martin et al., 2017; Woodall et al., 2017). There is also mounting evidence for the widespread distribution of non-plastic synthetic microfibres in the environment (Miller et al., 2017). Elevated synthetic microfibre levels have been linked to sewagesludge disposal sites (Browne et al., 2011) and wastewater treatment works (WWTWs) (Mani et al., 2015;

De Villiers, 2018). The most likely sources of these microfibres are wastewater deriving from the washing of synthetic clothing, fragmentation of fishing equipment such as ropes and nets, and the degradation of cellulose acetate in cigarette butts (Browne et al., 2011; Cole et al., 2011; Van Cauwenberghe et al., 2015). Studies have shown that washing machine effluent water may be the biggest source of microfibres to the environment, and that a single garment can shed $>1900$ fibres per wash (Browne et al., 2011).

The ecological significance of microplastic and synthetic microfibre pollution has become a global concern. Synthetic microfibre pollution and ingestion poses a potential threat to the health of not only marine and freshwater ecosystems (Browne et al., 2008; Sussarellu et al., 2016; Wegner et al., 2012; Taylor et al. 2016), but also humans. It is important to note

\footnotetext{
* To whom all correspondence should be addressed.

e-mail: Steph.devilliers@gmail.com

Received 2 August 2018, accepted in revised form 12 December 2018.
}

that at present, there is no scientific evidence for chemical, physical or vector-related impacts of microfibre ingestion on human health. Nevertheless, a hypothetical risk has been communicated by scientists and the media. That, and the serious nature of the potential risk factors, demand more research. The potential risks are also not confined to plastic microfibres. Rayon, a synthetic microfibre widely used in the fashion industry, is manufactured from a natural fibre, cellulose. However, when it is bleached, a by-product called dioxin is released, a persistent environmental pollutant that is highly toxic.

Several studies have demonstrated high levels of microplastic and microfibre pollution in the South African coastal environment (Naidoo et al., 2015; Nel and Froneman, 2015; Nel et al., 2017), as has been reported for meso-plastic debris (Ryan et al., 2018). There is now evidence for a significant association between microfibre pollution hotspots along South Africa's coastal environment and land-based sources of pollution, such as wastewater treatment works and, in some instances, rivers (De Villiers, 2018). Geographic differences in levels of microfibre pollution around the South African coastline (Fig. 1a) reflect South Africa's diverse environmental as well as socio-economic landscape (Fig. 2). To aid the expedient identification of key land-based vectors of microfibre pollution transport, and areas of most concern, this paper presents data for microfibre levels in river sediment samples, collected opportunistically during a coastal monitoring survey.

\section{METHODS}

Spot sampling of river bank sediments was conducted at 35 sites along the south and east coast of South Africa (Table 1; Fig. 1b). A $500 \mathrm{~cm}^{3}$ riverbank sediment sample was obtained by combining 3 samples taken randomly at accessible spots, at least $1 \mathrm{~m}$ apart from each other and within $5 \mathrm{~m}$ above the water's edge. Samples were taken to a depth of $5 \mathrm{~cm}$. Plastic sample bags were sealed and stored at room temperature until further processing. In the laboratory, $250 \mathrm{~cm}^{3}$ of sediment 

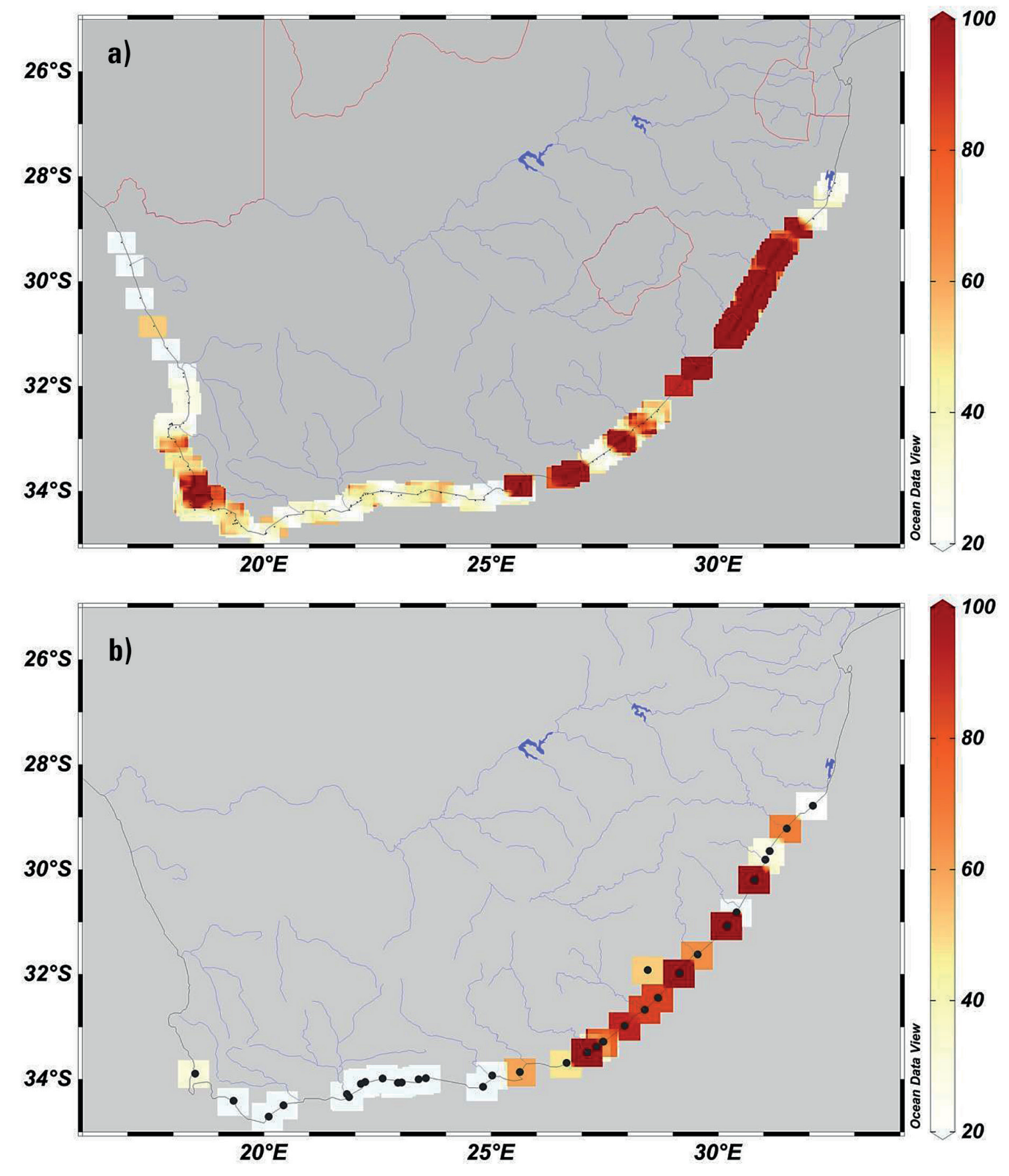

Figure 1

Abundance of microfibres in (a) beach (data from De Villiers, 2018) and (b) river bank sediments (tabulated in Table 1) along South Africa's coastline. Plotted values are microfibres $/ \mathrm{dm}^{3}$ of sediment.

sample was dried at $60^{\circ} \mathrm{C}$ in a glass beaker covered with aluminium foil. The dry sediment was then sieved through a $1 \mathrm{~mm}$ mesh metal sieve, and poured into a $2 \mathrm{dm}^{3}$ glass beaker containing a saturated $1.2 \mathrm{~g} / \mathrm{cm}^{3}$ sodium chloride $(\mathrm{NaCl})$ solution. The sediment- $\mathrm{NaCl}$ mixture was stirred with a glass rod for 2 to $3 \mathrm{~min}$ and the supernatant decanted through a 40 $\mu \mathrm{m}$ sieve. This was repeated 3 times with supersaturated $\mathrm{NaCl}$ and then 3 times with distilled water. The contents of the $40 \mu \mathrm{m}$ sieve was then carefully washed into a pre-cleaned glass petri dish, that was screened for contamination, covered and dried in an oven at $60^{\circ} \mathrm{C}$. Microfibres were identified and counted using a stereomicroscope (40x magnification), without transfer of the material from the petri dish, to minimize contamination and loss of material (De Villiers, 2018). Procedural blanks were included in each daily batch of samples processed, but no blank corrections were applied to the data, given that blank levels were consistently low or zero.

The microfibre abundance data $(n=35)$ is positively skewed (skewness $>3$ and kurtosis $>11$ ); the mean value is $68 \mathrm{~F} / \mathrm{dm}^{3}$ ( $73^{\text {rd }}$ percentile) and the median $28 \mathrm{~F} / \mathrm{dm}^{3}(47 \%$ percentile). Therefore, the non-parametric Spearman's rank correlation test was used for statistical data evaluation. Microfibre levels below 

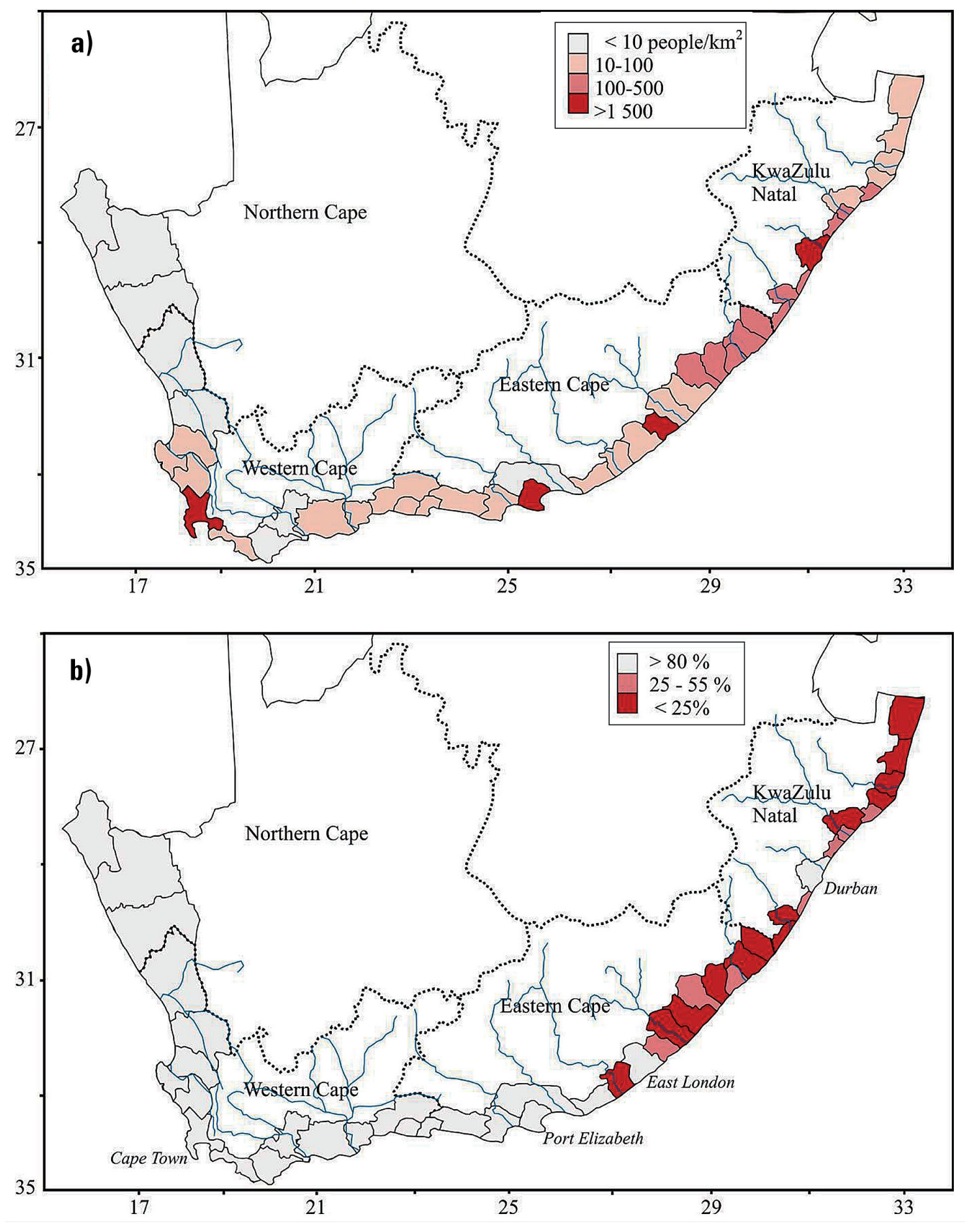

Figure 2

Plotted (a) population density (people/ $\mathrm{km}^{2}$ ) and (b) \% of households with access to piped water in dwelling or yards, for South Africa's coastal local municipalities (data from Statistics South Africa, 2012).

the median value will be referred to as 'low', values between the median and mean as 'elevated' and those above the mean as 'high'. No relationship between microfibre content and sediment particle size or organic content was evident in this sample set.
Identification of synthetic microfibres, based on visual inspection only, is prone to potential error and possible inclusion of natural fibres. This is particularly true for yellow fibres, that can easily be confused for plant cellulose fragments, and black fibres in organic-rich samples. FTIR 


\begin{tabular}{|c|c|c|c|c|c|c|}
\hline \multicolumn{7}{|c|}{$\begin{array}{l}\text { TABLE } 1 \\
\begin{array}{l}\text { Sediment sample locations, sampling dates and dry sediment microfibre content and density. Sediment density can be used to } \\
\text { convert } \# \mathrm{~F} / \mathrm{dm}^{3} \text { units to } \# \mathrm{~F} / \mathrm{kg} \text { for comparison purposes. }\end{array}\end{array}$} \\
\hline River system & Province & Latitude $\left({ }^{\circ} \mathbf{S}\right)$ & Longitude $\left({ }^{\circ} \mathrm{E}\right)$ & Sampling Date & $\# \mathrm{~F} / \mathrm{dm}^{3}$ & Density $\left(\mathrm{g} / \mathrm{cm}^{3}\right)$ \\
\hline Diep & WC & 33.891 & 18.485 & $2017 / 02 / 14$ & 33 & 1.43 \\
\hline Klein & WC & 34.408 & 19.329 & $2017 / 02 / 23$ & 12 & 1.10 \\
\hline Heuningnes & WC & 34.710 & 20.105 & $2017 / 02 / 23$ & 10 & 1.04 \\
\hline De Hoop Vlei & WC & 34.493 & 20.428 & $2017 / 02 / 25$ & 8 & 1.45 \\
\hline Gourits & WC & 34.337 & 21.874 & $2017 / 02 / 25$ & 4 & 1.33 \\
\hline Gourits & WC & 34.283 & 21.827 & $2017 / 02 / 25$ & 12 & 1.28 \\
\hline Klein Brak & WC & 34.086 & 22.131 & $2017 / 02 / 25$ & 8 & 1.28 \\
\hline Groot Brak & WC & 34.048 & 22.229 & $2017 / 02 / 25$ & 4 & 1.37 \\
\hline Touw & WC & 33.985 & 22.609 & $2017 / 02 / 25$ & 4 & 1.48 \\
\hline Goukamma & WC & 34.068 & 22.948 & $2017 / 02 / 26$ & 4 & 1.39 \\
\hline Knysna & WC & 34.059 & 23.033 & $2017 / 02 / 26$ & 4 & 1.38 \\
\hline Keurbooms & WC & 34.002 & 23.401 & $2017 / 02 / 26$ & 12 & 1.29 \\
\hline Groot & WC & 33.977 & 23.563 & $2017 / 02 / 26$ & 4 & 1.19 \\
\hline Krom & $\mathrm{EC}$ & 34.142 & 24.825 & $2017 / 02 / 27$ & 0 & 1.47 \\
\hline Gamtoos & EC & 33.927 & 25.024 & $2017 / 02 / 27$ & 8 & 1.40 \\
\hline Swartkops & EC & 33.863 & 25.632 & $2017 / 02 / 28$ & 60 & 1.46 \\
\hline Bushmans & EC & 33.688 & 26.661 & $2017 / 02 / 28$ & 48 & 1.37 \\
\hline Great Fish & $\mathrm{EC}$ & 33.490 & 27.125 & $2017 / 02 / 28$ & 380 & 1.49 \\
\hline Bhega & EC & 33.381 & 27.324 & $2017 / 03 / 01$ & 36 & 1.33 \\
\hline Keiskamma & EC & 33.284 & 27.472 & $2017 / 03 / 01$ & 28 & 1.53 \\
\hline Keiskamma & $\mathrm{EC}$ & 33.283 & 27.458 & $2017 / 03 / 01$ & 127 & 1.39 \\
\hline Nahoon & EC & 32.983 & 27.940 & $2017 / 03 / 01$ & 92 & 1.45 \\
\hline Great Kei & $\mathrm{EC}$ & 32.673 & 28.380 & $2017 / 03 / 02$ & 85 & 1.34 \\
\hline Qora & EC & 32.445 & 28.673 & $2017 / 03 / 10$ & 95 & 1.40 \\
\hline Qora & $\mathrm{EC}$ & 32.446 & 28.676 & $2017 / 03 / 10$ & 75 & 1.44 \\
\hline Ninga & $\mathrm{EC}$ & 31.979 & 29.149 & $2017 / 03 / 10$ & 180 & 1.35 \\
\hline Mbashe & $\mathrm{EC}$ & 31.919 & 28.448 & $2017 / 03 / 04$ & 52 & 1.47 \\
\hline Mzimvubu & $\mathrm{EC}$ & 31.620 & 29.546 & $2017 / 03 / 05$ & 65 & 1.14 \\
\hline Mtamvuna & $\mathrm{KZN}$ & 31.077 & 30.195 & $2017 / 03 / 05$ & 567 & 1.42 \\
\hline Mzimkulu & $\mathrm{KZN}$ & 30.819 & 30.404 & $2017 / 03 / 05$ & 16 & 1.49 \\
\hline Mkomaas & $\mathrm{KZN}$ & 30.201 & 30.801 & $2017 / 03 / 06$ & 208 & 1.59 \\
\hline Mgeni & $\mathrm{KZN}$ & 29.812 & 31.036 & $2017 / 03 / 06$ & 35 & 1.42 \\
\hline Mdloti & $\mathrm{KZN}$ & 29.648 & 31.130 & $2017 / 03 / 07$ & 28 & 1.65 \\
\hline Tugela & $\mathrm{KZN}$ & 29.220 & 31.507 & $2017 / 03 / 07$ & 68 & 1.20 \\
\hline Msingazi & $\mathrm{KZN}$ & 28.787 & 32.081 & $2017 / 03 / 07$ & 20 & 1.39 \\
\hline
\end{tabular}

spectroscopy should ideally be used for identification purposes, but was not available. FTIR is widely used to identify plastic microfibres, but it is important to also identify and quantify non-plastic synthetic microfibres (Taylor et al., 2016; Miller et al., 2017). Great care was taken to only count fibres that showed definitive synthetic characteristics, such as shape and colour. All samples were dominated by blue fibres, a colour that does not occur naturally, which makes fibre counts based on visual inspection only more robust. Microplastic and microfibre research, including sampling and analytical methodologies, are rapidly evolving. The methods used in this study were adapted from those widely used in the literature (Van Cauwenberghe et al., 2015), and are useful for surveys of this nature and when resources are limited. However, future studies should employ new proposed methodologies and more accurate identification methods. 


\section{RESULTS AND DISCUSSION}

The sediment microfibre contents of the 14 rivers sampled along the Cape South Coast (Klein to Gamtoos) are all low compared to the East Coast (Table 1, Fig. 2b). In contrast, only two of the remainder of the observations are low and 10 of the observations in the Eastern Cape and KwaZulu-Natal provinces are very high. This geographic pattern mirrors the large-scale differences observed in a study of beach sediments along $2700 \mathrm{~km}$ of South Africa's coastline (Fig. 1a, De Villiers, 2018). The latter study also identified microfibre hotspots near each of the four large coastal metropolitan areas (Cape Town, Port Elizabeth, East London and Durban), in the vicinity of coastal WWTW discharge points (De Villiers, 2018). In the Western Cape, the most abundant sediment microfibre levels were found in the Diep River, the largest river in the Cape Town metropolitan area. The Diep River sampling site is located downstream of the Potsdam WWTW, and elevated microfibre levels in its estuary are consistent with elevated levels in adjacent beach sediments (De Villiers, 2018). Elevated microfibre concentrations were also found in the Swartkops estuary located on the outskirts of the Port Elizabeth metropolitan area (Table 1). The evidence therefore suggests that WWTWs may result in elevated river and beach sediment microfibre levels in urban areas. More detailed sampling in the vicinity of these WWTWs is required.

The KwaZulu-Natal rivers sampled have elevated to very high levels of microfibres, compared to that of the Western Cape (Table 1), which was also the case for beach sediment (De Villiers, 2018). However, the results of the river and beach sediment studies differ in one important aspect, the highest average levels of river sediment microfibres are found away from major metropolitan areas, in particular, in the Wild Coast region in the Eastern Cape and rural coastal KwaZulu-Natal (Fig. 2b). These river catchments are located in areas with the highest population densities along the South African coast (Fig. 2a), outside of the four coastal metropolitan areas. Despite their relatively high population density, these areas are rural and relatively undeveloped. The latter is illustrated by the low percentage (less than 25\%) of households with access to piped water, either within the home or within the yard (Statistics South Africa, 2012).

Comparison of river sediment microfibre data with population density and socio-economic indicators such as access to water (Statistics South Africa, 2012) reveals a startling statistic (Fig. 3). River sediment microfibre abundance has a medium (Spearman's rho 0.30-0.49) to large (Spearman's rho $>0.5)$ and statistically significant $(P<0.005)$ relationship with population density when considered using census data for local municipalities (Fig. 3; Spearman's rho $=0.472, P<0.005$ ), and at the district municipal level (Spearman's rho $=0.635$, $P=4.15 \times 10^{-5}$ ). However, the association with the percentage of households with access to piped water (in the house or yard) is even stronger at the local (Spearman's rho $=-0.703$, $P=2.47 \times 10^{-6}$ ) and at the district (Spearman's rho $=-0.740$, $P=3.83 \times 10^{-7}$ ) municipality level.

\section{CONCLUSIONS}

The microfibre contents of the river sediments studied have a very strong positive and statistically significant association with socio-economic development indicators such as access to water. In rural KwaZulu-Natal, the majority of communities

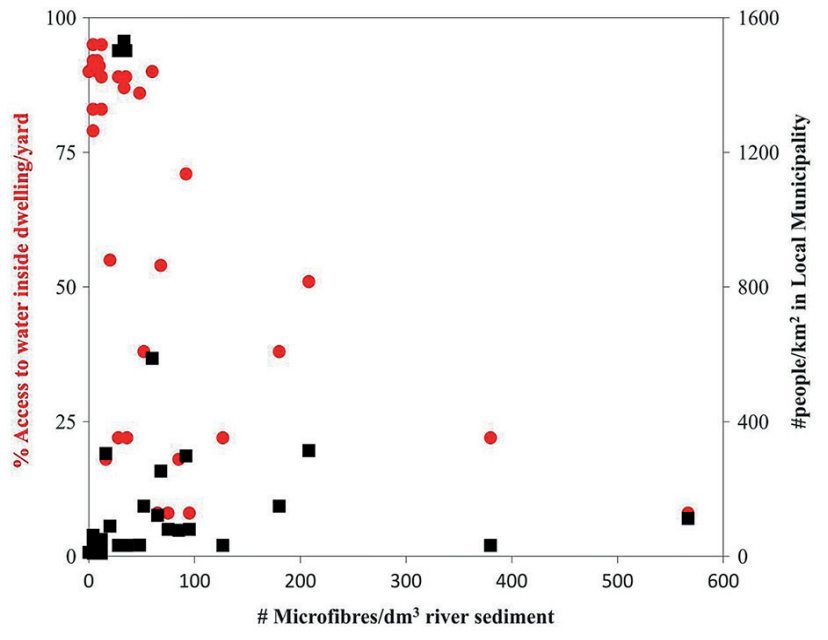

Figure 3

River sediment sample microfibre content, plotted against the \% of households with access to piped water (red circles), and population density (black squares) of the local municipality within which the sampling site is located.

who do not have access to piped water inside their house or yard, do have access to water at communal taps (Statistics South Africa, 2012). In the rural coastal areas of the northern Eastern Cape, however, this is not the case and the majority of people who do not have piped water inside the house or yard, also do not have access to water at a communal tap. These communities rely exclusively on river water, not only for extracting water for drinking and other domestic purposes, but also for directly washing clothes in. The abundance of perennial rivers and streams in this area makes this extensive and informal use of river water for domestic purposes possible.

Results for coastal beach sediment microfibre levels (De Villiers, 2018) hinted at a relationship between coastal sediment microfibre levels and access to piped water in rural coastal communities, and the results of this study further suggest it. The results of this study also suggest that the use of rivers for clothes washing activities, in rural communities for whom rivers are the only source of accessible water, represents a direct vector of microfibre transport to the environment. If microfibre ingestion is harmful to the health of aquatic ecosystems or humans, then such activities are harmful to communities and ecosystems downstream from areas where these activities are an everyday occurrence. Efforts to study microplastic and microfibre pollutant pathways should therefore include focus on communities and areas who do not have access to water infrastructure.

\section{ACKNOWLEDGEMENTS}

The time and contribution of two anonymous referees are much appreciated.

\section{REFERENCES}

BROWNE MA, CRUMP P, NIVEN SJ, TEUTEN E, TONKIN A, GALLOWAY TS and THOMPSON RC (2011) Accumulation of microplastic on shorelines worldwide: sources and sinks. Environ. Sci. Technol. 45 9175-9179. https://doi.org/10.1021/es201811s

BROWNE MA, GALLOWAY TS and THOMPSON RC (2010) Spatial patterns of plastic debris along estuarine shorelines. Environ. Sci. Technol. 44 3404-3409. https://doi.org/10.1021/es903784e 
BROWNE MA, DISSANAYAKE A, GALLOWAY TS, LOWE DM and THOMPSON RC (2008) Ingested microscopic plastic translocates to the circulatory system of the mussel, Mytilus edulis (L.). Environ. Sci. Technol. 42 5026-5031. https://doi.org/10.1021/es800249a

COLE M, LINDEQUE P, HALSBAND C and GALLOWAY TS (2011) Microplastics as contaminants in the marine environment: a review. Mar. Pollut. Bull. 62 2588-2597. https://doi.org/10.1016/j. marpolbul.2011.09.025

DE VILLIERS (2018) Quantification of microfibre levels in South Africa's beach sediments, and evaluation of spatial and temporal variability from 2016 to 2017. Mar. Pollut. Bull. 135 481-489. https://doi.org/10.1016/j.marpolbul.2018.07.058

ERIKSEN M, LEBRETON LCM, CARSON HS, THIEL M, MOORE CJ, BORERRO JC, GALGANI F, RYAN PG and REISSER J (2014) Plastic pollution in the World's oceans: more than 5 trillion plastic pieces weighing over 250,000 tons afloat at sea. PloS One 9 e111913. https://doi.org/10.1371/journal.pone.0111913

JAMBECK JR, GEYER R, WILCOX C, SIEGLER TR, PERRYMAN M, ANDRADY A, NARAYAN R and LAW KL (2015) Plastic waste inputs from land into the ocean. Science 347 768-771. https://doi. org/10.1126/science.1260352

HURLEY R, WOODWARD J and ROTHWELL JJ (2018) Microplastic contamination of river beds significantly reduced by catchmentwide flooding. Nat. Geosci. 11 251-257. https:/doi.org/10.1038/ s41561-018-0080-1

MANI T, HAUK A, WALTER U and BURKHARDT-HOLM P (2016) Microplastic profile along the Rhine River. Sci. Rep. 517988. https://doi.org/10.1038/srep17988

MARTIN J, LUSHER A, THOMPSON RC and MORLEY A (2017) The deposition and accumulation of microplastics in marine sediments and bottom water from the Irish continental shelf. Sci. Rep. 7 107722. https://doi.org/10.1038/s41598-017-11079-2

MATHALON A and HILL P (2014) Microplastic fibres in the intertida ecosystem surrounding Halifax Harbor, Nova Scotia. Mar. Pollut Bull. 81 69-79. https://doi.org/10.1016/j.marpolbul.2014.02.018

MILLER RZ, WATTS AJR, WINSLOW BO, GALLOWAY TS and BARROWS APW (2017) Mountains to the sea: river study of plastic and non-plastic microfibre pollution in the northeast USA. Mar. Poll. Bull. 124 245-251. https://doi.org/10.1016/j. marpolbul.2017.07.028

NAIDOO T, GLASSOM D and SMIT AJ (2015) Plastic pollution in five urban estuaries of KwaZulu-Natal, South Africa. Mar. Pollut. Bull. 101 473-480. https://doi.org/10.1016/j.marpolbul.2015.09.044

NEL HA, HEAN JW, NOUNDOU XS and FRONEMAN PW (2017) Do microplastic load reflect the population demographics along the southern African coastline? Mar. Pollut. Bull. 115 115-119. https:// doi.org/10.1016/j.marpolbul.2016.11.056

NEL HA and FRONEMAN PW (2015) A quantitative analysis of microplastic pollution along the south-eastern coastline of South Africa. Mar. Pollut. Bull. 101 274-279. https://doi.org/10.1016/j. marpolbul.2015.09.043

RYAN PG, PEROLD V, OSBORNE A and MOLONEY CL (2018) Consistent patterns of debris on South African beaches indicate that industrial pellets and other mesoplastic items mostly derive from local sources. Environ. Poll. 238 1008-1016. https://doi. org/10.1016/j.envpol.2018.02.017

STATISTICS SOUTH AFRICA (2012) Census 2011: Provinces at a glance. Report 03-01-43, Statistics South Africa, Pretoria. $82 \mathrm{pp}$.

SUSSARELLU R, SUQUET M, THOMAS Y, LAMBERT C, FABIOUX C, PERNET ME, LE GOIC N, QUILLIEN V, MINGANT C, EPELBOIN Y, CORPOREAU C, GUYOMARCH J, ROBBENS J, PAUL-PONT I, SOUDANI P and HUVET A (2016) Oyster reproduction is affected by exposure to polystyrene microplastics. Proc. Nat. Acad. Sci. 113 2430-2435. https://doi.org/10.1073/ pnas. 1519019113

TAYLOR ML, GWINNETT C, ROBINSON LF and WOODALL LC (2016) Plastic microfibre ingestion by deep-sea organisms. Sci. Rep. 6 33997. https://doi.org/10.1038/srep33997

VAN CAUWENBERGHE L, DEVRIESE L, GALGANI F, ROBBENS J and JANSSEN CR (2015) Microplastics in sediments: a review of techniques, occurrence and effects. Mar. Environ. Res. 111 5-17. https://doi.org/10.1016/j.marenvres.2015.06.007

WEGNER A, BESSELING E, FOEKEMA EM, KAMERMANS P and KOELMANS AA (2012) Effects of nanopolystyrene on the feeding behaviour of the Blue Mussel (Mytilus edulis L.). Environ. Toxicol. Chem. 31 2490-2497. https://doi.org/10.1002/etc.1984

WOODALL LC, SANCHEZ-VIDAL A, CANALS M, PAPTERSON GLJ, COPPOCK R, SLEIGHT V, CALAFAT A, ROGERS AD, NARAYANASWAMY BE and THOMPSON RC (2017) The deep sea is a major sink for microplastic debris. R. Soc. Open Sci. 1 140317. https://doi.org/10.1098/rsos.140317 